\title{
The effect of co-infestation by conspecific and heterospecific aphids on the feeding behaviour of Nasonovia ribisnigri on resistant and susceptible lettuce cultivars
}

\author{
Cindy J. M. ten Broeke ${ }^{1}$ (D) Marcel Dicke ${ }^{1} \cdot$ Joop J. A. van Loon ${ }^{1}$
}

Received: 20 February 2017 / Accepted: 18 April 2017/Published online: 20 May 2017

(C) The Author(s) 2017. This article is an open access publication

\begin{abstract}
Aphid saliva can suppress the blocking of sieve elements, a reaction that plants employ to inhibit aphid feeding, but aphid saliva can also elicit plant defence responses. Such plant responses might affect interactions between different aphid species and intraspecifically, e.g. among different biotypes. The objectives of our study were to investigate if feeding behaviour and performance of two biotypes of the lettuce aphid Nasonovia ribisnigri are affected by (1) feeding by the other biotype and (2) feeding by the green peach aphid Myzus persicae or the potato aphid Macrosiphum euphorbiae. Additionally the effect of feeding in a group was studied. All experiments were performed on both a resistant and an isogenic susceptible lettuce cultivar. Feeding or probing by conspecific or heterospecific aphids had different effects on Nasonovia ribisnigri biotypes. Aphids were only slightly affected by feeding or probing of the same biotype on both susceptible and resistant lettuce. N. ribisnigri virulent biotype $\mathrm{Nr}: 1$ suppressed the resistance against Nr:0 in the resistant cultivar. In contrast, defence was induced by $\mathrm{Nr}: 1$ against $\mathrm{Nr}: 0$ in susceptible lettuce. Co-infestation by M. euphorbiae and M. persicae had minor effects on Nr:0. Defence against $\mathrm{Nr}: 1$ was induced on both susceptible lettuce and resistant lettuce by Nr:0 and M. euphorbiae. Additionally, M. persicae induced defence in resistant lettuce against $\mathrm{Nr}: 1$. Effectors in the saliva of Nr:1 aphids are likely responsible for the defence suppression in lettuce. Identification of
\end{abstract}

Handling Editor: Ritu Chaudhary.

Cindy J. M. ten Broeke

cindytenbroeke@gmail.com

1 Laboratory of Entomology, Wageningen University, P.O. 16, 6700 AA Wageningen, The Netherlands these effectors could lead to a better understanding of the mechanism of virulence in $N$. ribisnigri.

Keywords Lettuce Aphid · Virulence - Co-infestation · Suppression

\section{Introduction}

Nasonovia ribisnigri (Mosely), the black currant-lettuce aphid, is an important pest of lettuce, causing significant economic losses in the lettuce industry (McCreight 2008). Control of this aphid was based on host plant resistance conferred by the $\mathrm{Nr}$-gene, originating from Lactuca virosa L. (a distant wild relative of cultivated lettuce), which provided near-complete resistance against this aphid (Reinink and Dieleman 1989). This resistance, however, is no longer effective, because virulent populations of $N$. ribisnigri, designated as biotype $\mathrm{Nr}: 1$, have been reported infesting resistant lettuce since 2007 (Thabuis et al. 2011).

The exact resistance mechanism encoded by the $\mathrm{Nr}$-gene is still unknown. However, resistance components were shown to operate during the pathway of the aphid stylets to the phloem and when in the phloem itself (Ten Broeke et al. 2013), inhibiting and blocking sustained feeding of avirulent $N$. ribisnigri, biotype $\mathrm{Nr}: 0$. Nr:0 aphids are not able to ingest phloem and cannot survive on resistant lettuce. In contrast, $\mathrm{Nr}: 1$ aphids are able to survive and ingest phloem of resistant lettuce, performing equally well on resistant and susceptible lettuce cultivars (Ten Broeke et al. 2013). The mechanism underlying the virulence of $\mathrm{Nr}: 1$ aphids is unknown. It is hypothesised that the ability of virulent aphid biotypes to overcome $R$-gene-based resistance could be attributed to the loss or modification of avirulence gene products, thereby suppressing plant 
defences and/or evading recognition by the plant (Hogenhout and Bos 2011; Parker and Gilbert 2004).

Aphid saliva plays an important role in suppressing the blocking of sieve elements and the food channel in the aphid's stylets (Will et al. 2007). In contrast, the saliva of aphids may also act as an elicitor of plant defences (Cherqui and Tjallingii 2000). Because aphids induce plant defences, pre-infestation of plants by aphids might affect the behaviour and performance of other aphids. The effect of previous infestation on aphids that subsequently attack the plant depends on the aphid species. For example, intraspecific pre-infestation of Vicia faba (L.) had beneficial effects for Aphis fabae (Scopoli); however, Rhopalosiphum padi (Linnaeus) did not seem to benefit from intraspecific pre-infestation of Triticum aestivum L. (Prado and Tjallingii 1997). Increase in susceptibility after pre-infestation was found by Civolani et al. (2010) for Myzus persicae (Sulzer) on susceptible tomato, Lycopersicon esculentum $\mathrm{L}$.

Different biotypes of the same aphid species may influence each other's performance on resistant and susceptible plants. For example, pre-infestation of $T$. aestivum by a virulent biotype of Schizaphis graminum (Rondani) increased the susceptibility of the plant to an avirulent biotype of this species (Dorschner et al. 1987). In contrast, Hebert et al. (2007) found that a virulent isolate of Macrosiphum euphorbiae (Thomas) did not enhance the performance of avirulent M. euphorbiae. The first objective of our study was to investigate the effect of co-infestation of virulent biotype Nr:1 of $N$. ribisnigri on the feeding behaviour and performance of avirulent biotype $\mathrm{Nr}: 0$ and vice versa, on both a susceptible and resistant lettuce cultivars. Although many previous studies focus on the effect of pre-infestation on aphid behaviour or performance, we investigated the effect of pre-infestation and simultaneous feeding or probing by aphids on the behaviour of other aphids; the aphids initially inoculated were left on the plants during the experiments. We refer to the effect of feeding or probing by aphids, because in the treatment in which Nr:0 aphids were inoculated on the resistant cultivar, sustained feeding probably did not occur. To study the effect of feeding in a group, we also investigated the effect of feeding by the same biotype on $\mathrm{Nr}: 0$ and $\mathrm{Nr}: 1$ aphids on the two lettuce cultivars.

Both $M$. persicae and M. euphorbiae occur on lettuce crops. The $N r$-gene confers partial resistance against certain M. persicae isolates and has no effect on M. euphorbiae (Reinink and Dieleman 1989). The second objective of our study was to investigate the effect of co-infestation by $M$. persicae or M. euphorbiae on the feeding behaviour and performance of $\mathrm{Nr}: 0$ and $\mathrm{Nr}: 1$ biotypes of $\mathrm{N}$. ribisnigri on a susceptible and resistant lettuce cultivar. The performance of both $M$. persicae and M. euphorbiae on both the susceptible and the resistant lettuce cultivar was evaluated to check if the aphids performed equally well on both cultivars.

\section{Materials and methods}

\section{Plants and aphids}

The plants used in the experiments were two near-isogenic L. sativa cultivars, i.e. Corbana, carrying the $\mathrm{Nr}$-gene and resistant to $N$. ribisnigri $\mathrm{Nr}: 0$, and Terlana, susceptible to Nr:0 and Nr:1 aphids; both supplied by Enza Zaden, Enkhuizen, The Netherlands. Plants were grown in a greenhouse compartment at $18-20{ }^{\circ} \mathrm{C}, 60 \% \mathrm{RH}$ and $14-/$ 10-h photoperiod. The potting soil was treated with ENTONEM (a formulation of the entomopathogenic nematode, Steinernema feltiae, www.koppert.com) once a week, to control soil infestation by larvae of sciarid flies. Three-week-old plants were used for the experiments.

Two biotypes of $N$. ribisnigri, $\mathrm{Nr}: 0$ and $\mathrm{Nr}: 1$ were used in the experiments. Nr:0 aphids (collected in The Netherlands in 2001) were reared on Terlana, and Nr:1 aphids (collected in Germany in 2007) were reared on Corbana, in a greenhouse compartment at $18-20{ }^{\circ} \mathrm{C}, 60 \% \mathrm{RH}$ and $14-/$ 10-h photoperiod. Both M. euphorbiae and M. persicae were reared on Corbana, under the same climatic condition as the $N$. ribisnigri populations. In the colonies of $N$. ribisnigri and $M$. euphorbiae, both alate and apterous adults were present. In the rearing of $M$. persicae, only apterous adults were present.

\section{EPG recording}

To study the effect of co-infestation on the feeding behaviour of $N$. ribisnigri, the electrical penetration graph technique (EPG) was used. This technique allows the electrical recording of the feeding behaviour of aphids and other piercing-sucking insects. In the EPG set-up, a plant and a piercing insect are made part of an electrical circuit, by attaching a thin gold wire to the insect's dorsum and inserting an electrode in the soil of the plant. For details on the EPG methods used see Ten Broeke et al. (2013). Eight hour recordings were made from winged adult aphids (alatae) of unknown age of $N$. ribisnigri and $M$. euphorbiae aphids. For M. persicae, wingless adults were used due to the absence of winged aphids in the rearing. The EPG patterns that we distinguished in the analysis were stylet pathway $(\mathrm{C})$, non-penetration period (NP), phloem phase (E), phloem salivation (E1), phloem ingestion (E2), xylem ingestion $(\mathrm{G})$ and penetration difficulties $(\mathrm{F})$.

Each biotype of $N$. ribisnigri was tested in a group of 10 aphids, e.g. other biotype of $N$. ribisnigri, the same biotype 
of $N$. ribisnigri, $M$. euphorbiae and $M$. persicae on both Corbana and Terlana plants (Table 1). Additionally, all aphid biotypes and species were also tested separately on Corbana and Terlana plants as a control. Two days prior to EPG recordings, plants were infested by placing 10 third/fourth-instar nymphs on a leaf, contained a in clip cage (ten Broeke et al. 2016). The clip cage was removed before recording, and a foam ring was placed around the aphids to contain them on the leaf during the EPG recording. The test aphid was placed on the leaf in the middle of the 10 nymphs. For every treatment (Table 1), 24 replicates were recorded. Every aphid and plant individual was only used once. Incomplete recordings were excluded from the analyses, leaving between 17 and 23 replicates per treatment.

\section{Performance test}

Performance of the two biotypes of $N$. ribisnigri in all treatments (see Table 1) was measured by assessing nymphal survival and development time from nymph to the adult stage.

For the co-infestation treatments, ten 76-h-old nymphs of the treatment aphid were transferred to a leaf and contained in a clip cage. After one day, five 24-h-old nymphs of the test aphid were transferred into the clip cages with the treatment aphids. Treatment aphids that turned into

Table 1 Experimental treatments investigated, in terms of test plant, test aphids and aphid biotype or species co-infested

\begin{tabular}{lll}
\hline Test plant & Test aphid & Treatment \\
\hline Terlana & Nr:0 & - \\
Terlana & Nr:0 & Nr:0 \\
Terlana & Nr:0 & Nr:1 \\
Terlana & Nr:0 & Macrosiphum euphorbiae \\
Terlana & Nr:0 & Myzus persicae \\
Corbana & Nr:0 & - \\
Corbana & Nr:0 & Nr:0 \\
Corbana & Nr:0 & Nr:1 \\
Corbana & Nr:0 & Macrosiphum euphorbiae \\
Corbana & $\mathrm{Nr}: 0$ & Myzus persicae \\
Terlana & $\mathrm{Nr}: 1$ & - \\
Terlana & $\mathrm{Nr}: 1$ & Nr:1 \\
Terlana & $\mathrm{Nr}: 1$ & Nr:0 \\
Terlana & $\mathrm{Nr}: 1$ & Macrosiphum euphorbiae \\
Terlana & $\mathrm{Nr}: 1$ & Myzus persicae \\
Corbana & $\mathrm{Nr}: 1$ & - \\
Corbana & $\mathrm{Nr}: 1$ & Nr:1 \\
Corbana & $\mathrm{Nr}: 1$ & Nr:0 \\
Corbana & $\mathrm{Nr}: 1$ & Macrosiphum euphorbiae \\
Corbana & $\mathrm{Nr}: 1$ & Myzus persicae \\
\hline
\end{tabular}

adults during the experiments were replaced by nymphs, to prevent an increase in density of treatment aphids due to reproduction. For the combinations, Nr:0/Nr: 1 colour differences between the biotypes allowed distinction, whereas for the Nr:0/Nr:0 and Nr:1/Nr:1 combination, the difference in developmental stage allowed distinction. For the control experiments (no co-infestation), five 24-h-old nymphs were transferred to a lettuce leaf and contained in a clip cage.

The mortality and the developmental stage of the test aphids were recorded daily until they reached the adult stage. To obtain 24-h-old nymphs, about 150 adult aphids were kept in Petri dishes on leaves of cultivar Terlana (Nr:0) or Corbana (Nr:1, M. euphorbiae and M. persicae) for $24 \mathrm{~h}$. Experiments were conducted in a greenhouse compartment at a temperature of $18-20{ }^{\circ} \mathrm{C}, 60 \% \mathrm{RH}$ and 14-/10-h photoperiod. For every treatment, 20 plants were tested.

\section{Statistics}

All statistical tests were performed with IBM SPSS Statistics version 19. EPG parameters were calculated for every aphid tested using the EPG analysis worksheet created by Sarria et al. (2009). The Mann-Whitney $U$ test was used for pairwise comparisons between different treatments applying the Bonferroni correction for multiple comparisons. Fisher's exact test was performed to analyse differences in the percentage of aphids that showed phloem ingestion (E2). For aphid performance, every plant was considered one replicate. Results were first calculated per plant, and means and standard error were calculated over all plants. The Mann-Whitney $U$ test was used to test for significant differences in aphid mortality (in the performance experiment), time until mortality and development time as an effect of treatment.

\section{Results}

\section{Effects of feeding in a group of the same biotype}

No significant differences were found between Nr:0 aphids feeding in a group and single aphids on cultivar Terlana (Tables 2, 3; 5 in Appendix; Fig. 1b). On Corbana, Nr:0 aphids in a group displayed a higher number of probes $(P=0.001)$ compared to single aphids. Performance was not affected (Table 3 ).

Nr:1 aphids in a group on Terlana displayed a higher number of probes $(P=0.001)$ compared to single aphids on Terlana (Table 2; Fig. 1d). On Corbana, EPG parameters of Nr:1 aphids in a group did not differ significantly from single Nr:1 aphids. 
Table 2 EPG parameters (mean \pm SEM) of $N$. ribisnigri population $\mathrm{Nr}: 0$ and $\mathrm{Nr}: 1$ on $L$. sativa cultivars, Corbana $(\mathrm{C})$ and Terlana (T) as single aphids or in a group of Nr:0, Nr:1, M. euphorbiae (Macro) and M. persicae (Myzus)

\begin{tabular}{|c|c|c|c|c|c|}
\hline $\begin{array}{l}\text { Test aphid: } \\
\text { Nr:0 }\end{array}$ & $\begin{array}{l}\mathrm{T} \\
(n=20)\end{array}$ & $\begin{array}{l}\mathrm{T}(\mathrm{Nr}: 0) \\
(n=18)\end{array}$ & $\begin{array}{l}\mathrm{T}(\mathrm{Nr}: 1) \\
(n=23)\end{array}$ & $\begin{array}{l}\text { T(Macro) } \\
(n=21)\end{array}$ & $\begin{array}{l}\text { T(Myzus) } \\
(n=22)\end{array}$ \\
\hline Duration of first NP & $366 \pm 115$ & $154 \pm 41$ & $519 \pm 274$ & $423 \pm 95$ & $337 \pm 64$ \\
\hline Time to 1 st visible $\mathrm{E}$ from start 1 st probe & $5879 \pm 1007$ & $5239 \pm 901$ & $7485 \pm 1237$ & $5814 \pm 8120$ & $4706 \pm 553$ \\
\hline Contribution E1 to E (\%) & $1.64 \pm 0.55$ & $7.24 \pm 4.29$ & $12.91 \pm 6.05^{* *}$ & $5.73 \pm 3.90$ & $21.37 \pm 7.50 *$ \\
\hline$\%$ aphids showing E2 & 100 & 86 & 87 & 100 & 86 \\
\hline Number of probes & $8.45 \pm 1.53$ & $12.29 \pm 2.31$ & $11.78 \pm 1.64$ & $11.00 \pm 2.20$ & $16 \pm 2.60^{*}$ \\
\hline $\begin{array}{l}\text { Test aphid: } \\
\text { Nr:0 }\end{array}$ & $\begin{array}{l}\mathrm{C} \\
(n=19)\end{array}$ & $\begin{array}{l}\mathrm{C}(\mathrm{Nr}: 0) \\
(n=23)\end{array}$ & $\begin{array}{l}\text { C(Nr:1) } \\
(n=18)\end{array}$ & $\begin{array}{l}\text { C(Macro) } \\
(n=21)\end{array}$ & $\begin{array}{l}\text { C(Myzus) } \\
(n=23)\end{array}$ \\
\hline Duration of first NP & $417 \pm 142$ & $315 \pm 140$ & $339 \pm 95$ & $120 \pm 22$ & $485 \pm 110$ \\
\hline Time to 1 st visible $E$ from start 1 st probe & $7643 \pm 1350$ & $12,010 \pm 1894$ & $8755 \pm 1250$ & $10,275 \pm 1287$ & $8915 \pm 1415$ \\
\hline Contribution E1 to E (\%) & $98.66 \pm 0.99$ & $97.52 \pm 2.48$ & $74.78 \pm 8.43$ & $89.96 \pm 4.39$ & $87.67 \pm 7.12$ \\
\hline$\%$ aphids showing E2 & 10 & 6 & $42 *$ & 24 & 13 \\
\hline Number of probes & $27.05 \pm 2.11$ & $43.67 \pm 3.79 * * *$ & $34.16 \pm 3.34$ & $46.67 \pm 2.87 * * *$ & $41.78 \pm 3.18 * * *$ \\
\hline $\begin{array}{l}\text { Test aphid: } \\
\text { Nr:1 }\end{array}$ & $\begin{array}{l}\mathrm{T} \\
(n=19)\end{array}$ & $\begin{array}{l}\mathrm{T}(\mathrm{Nr}: 1) \\
(n=22)\end{array}$ & $\begin{array}{l}\mathrm{T}(\mathrm{Nr}: 0) \\
(n=22)\end{array}$ & $\begin{array}{l}\text { T(Macro) } \\
(n=20)\end{array}$ & $\begin{array}{l}\text { T(Myzus) } \\
(n=17)\end{array}$ \\
\hline Duration of first NP & $400 \pm 112$ & $199 \pm 69$ & $217 \pm 35$ & $719 \pm 220$ & $166 \pm 74$ \\
\hline Time to 1 st visible $\mathrm{E}$ from start 1 st probe & $3959 \pm 716$ & $4089 \pm 576$ & $7242 \pm 1171$ & $5499 \pm 1131$ & $5315 \pm 1288$ \\
\hline Contribution E1 to E (\%) & $4.69 \pm 1.95$ & $7.92 \pm 2.88$ & $22.10 \pm 7.89 *$ & $19.97 \pm 6.20 * *$ & $17.89 \pm 8.04$ \\
\hline$\%$ aphids showing E2 & 100 & 100 & 82 & 90 & 88 \\
\hline Number of probes & $9.05 \pm 1.74$ & $15.18 \pm 1.75^{*}$ & $13.95 \pm 1.72$ & $22.25 \pm 3.51^{* *}$ & $16.53 \pm 3.64 * * *$ \\
\hline $\begin{array}{l}\text { Test aphid: } \\
\text { Nr:1 }\end{array}$ & $\begin{array}{l}\mathrm{C} \\
(n=20)\end{array}$ & $\begin{array}{l}\mathrm{C}(\mathrm{Nr}: 1) \\
(n=18)\end{array}$ & $\begin{array}{l}\mathrm{C}(\mathrm{Nr}: 0) \\
(n=20)\end{array}$ & $\begin{array}{l}\text { C(Macro) } \\
(n=18)\end{array}$ & $\begin{array}{l}\text { C(Myzus) } \\
(n=19)\end{array}$ \\
\hline Duration of first NP & $464 \pm 119$ & $368 \pm 130$ & $519 \pm 181$ & $647 \pm 201$ & $402 \pm 77$ \\
\hline Time to 1 st visible $\mathrm{E}$ from start 1 st probe & $4181 \pm 694$ & $5881 \pm 1236$ & $10,232 \pm 1511 * * *$ & $6900 \pm 1154$ & $6347 \pm 832$ \\
\hline Contribution E1 to E (\%) & $5.09 \pm 1.55$ & $15.76 \pm 6.74$ & $40.94 \pm 10.03 * * *$ & $47.39 \pm 9.61 * * *$ & $5.70 \pm 1.90$ \\
\hline$\%$ aphids showing E2 & 100 & 94 & $65^{* *}$ & $72 *$ & 95 \\
\hline Number of probes & $7.30 \pm 1.55$ & $16.94 \pm 3.62$ & $22.30 \pm 3.39 * * *$ & $30.39 \pm 3.54 * * *$ & $18.05 \pm 2.27 * *$ \\
\hline
\end{tabular}

Pairwise comparisons were made for EPG parameters between plants without other aphids and plants with other aphids, and were analysed by the Mann-Whitney $U$ test, applying the Bonferroni correction to account for the four comparisons made by setting $\alpha=0.013$. Significance of differences in percentage of aphids showing E2 was analysed by Fisher's exact test. Time parameters are in seconds

$N P$ non-penetration, $E$ phloem event, $E 1$ phloem salivation and $E 2$ phloem ingestion

$* P<0.013 ; * * P<0.005 ; * * * P<0.001$

\section{Effects of Nr:1 on Nr:0 aphids}

Nr:0 aphids placed in a group of Nr:1 aphids on Terlana spent less time in the phloem phase $(P=0.003)$, of which $14 \%$ was spent on salivation, compared to $2 \%$ for single Nr:0 aphids $(P=0.001)$ (Tables $2 ; 5$ in Appendix). Significantly less time was spent on phloem ingestion $(P=0.006)$ (Fig. 1b) by Nr:0 aphids in an Nr:1 group compared to individual aphids. Development time was longer in an Nr:1 group compared to single aphids $(P<0.0001)$ (Table 3).
On Corbana, the percentage of $\mathrm{Nr}: 0$ aphids displaying phloem ingestion was higher in an Nr:1 group compared to single Nr:0 aphids $(P=0.013$; Tables 2; 5 in Appendix; Fig. 1). None of the single Nr:0 aphids survived the performance test on Corbana; however, $15 \%$ survived in a group of Nr:1 aphids $(P=0.001)$ (Table 3$)$.

\section{Effects of Nr:0 on Nr:1 aphids}

Nr:1 aphids placed in a group of Nr:0 aphids on Terlana spent less time on phloem events $(P=0.005)$ compared to 
Table 3 Performance parameters (mean \pm SEM) for the $N$. ribisnigri population $\mathrm{Nr}: 0$ and $\mathrm{Nr}: 1$ on $L$. sativa cultivars, Corbana (C) and Terlana (T) as single aphids or in a group of Nr:0, Nr:1, M. euphorbiae (Macro) and M. persicae (Myzus)

\begin{tabular}{|c|c|c|c|c|c|}
\hline Test aphid: Nr:0 & $\mathrm{T}$ & $\mathrm{T}(\mathrm{Nr}: 0)$ & $\mathrm{T}(\mathrm{Nr}: 1)$ & T(Macro) & T(Myzus) \\
\hline$\%$ aphids survived & $90 \pm 3.08$ & $94 \pm 2.20$ & $88 \pm 3.09$ & $91 \pm 2.70$ & $93 \pm 3.00$ \\
\hline Age at death & $3.50 \pm 0.42$ & $3.83 \pm 0.79$ & $4.23 \pm 0.46$ & $3.06 \pm 0.43$ & $3.30 \pm 0.49$ \\
\hline Development time & $8.63 \pm 0.10$ & $8.24 \pm 0.20$ & $9.97 \pm 0.13^{* * *}$ & $9.25 \pm 0.12 * * *$ & $8.79 \pm 0.23$ \\
\hline Test aphids: Nr:0 & $\mathrm{C}$ & $\mathrm{C}(\mathrm{Nr}: 0)$ & $\mathrm{C}(\mathrm{Nr}: 1)$ & C(Macro) & C(Myzus) \\
\hline$\%$ aphids survived & 0 & 0 & $15 \pm 4.34 * *$ & $7 \pm 3.00$ & $4 \pm 2.34$ \\
\hline Age at death & $3.17 \pm 0.12$ & $3.36 \pm 0.15$ & $4.26 \pm 0.32 * *$ & $3.88 \pm 0.19^{*}$ & $4.21 \pm 0.23^{* *}$ \\
\hline Development time & & & $13.13 \pm 0.52$ & $12.00 \pm 0.56$ & $12.00 \pm 0.00$ \\
\hline Test aphid: Nr:1 & $\mathrm{T}$ & $\mathrm{T}(\mathrm{Nr}: 1)$ & $\mathrm{T}(\mathrm{Nr}: 0)$ & $\mathrm{T}$ (Macro) & T(Myzus) \\
\hline$\%$ aphids survived & $88 \pm 3.37$ & $80 \pm 4.34$ & $87 \pm 3.67$ & $92 \pm 2.25$ & $91 \pm 2.70$ \\
\hline Age at death & $3.38 \pm 0.59$ & $3.38 \pm 0.30$ & $3.89 \pm 0.49$ & $5.00 \pm 0.94$ & $4.44 \pm 0.64$ \\
\hline Development time & $9.88 \pm 0.19$ & $9.28 \pm 0.21$ & $8.70 \pm 0.13 * * *$ & $10.31 \pm 0.23$ & $9.87 \pm 0.13$ \\
\hline Test aphid: Nr:1 & $\mathrm{C}$ & $\mathrm{C}(\mathrm{Nr}: 1)$ & $\mathrm{C}(\mathrm{Nr}: 0)$ & C(Macro) & C(Myzus) \\
\hline$\%$ aphids survived & $84 \pm 3.46$ & $78 \pm 3.45$ & $87 \pm 3.33$ & $87 \pm 3.94$ & $89 \pm 3.12$ \\
\hline Age at death & $3.38 \pm 0.32$ & $3.27 \pm 0.39$ & $4.45 \pm 0.57$ & $3.98 \pm 0.37$ & $3.61 \pm 0.33$ \\
\hline Development time & $9.32 \pm 0.14$ & $9.28 \pm 0.14$ & $9.32 \pm 0.12$ & $10.03 \pm 0.16^{*}$ & $10.25 \pm 0.25 *$ \\
\hline
\end{tabular}

Pairwise comparisons were made for performance parameters between plants without other aphids and plants with other aphids, and were analysed by the Mann-Whitney $U$ test, applying the Bonferroni correction to account for the 4 comparisons made by setting $\alpha=0.013$

$* P<0.013 ; * * P<0.005 ; * * * P<0.001$ single Nr:1 aphids (Table 5 in Appendix). The phloem phase consisted for $24 \%$ out of salivation for Nr: 1 aphids in an Nr:0 group compared to 5\% for single aphids $(P=0.011)$. Development time was shorter for Nr:1 aphids in an Nr:0 group compared to single Nr:1 aphids $(P=0.005)$ (Table 3)

On Corbana, Nr:1 aphids in an Nr:0 group displayed a higher number of probes $(P<0.0001)$, spent less time in the phloem phase $(P<0.0001)$ and on phloem ingestion $(P=0.007)$, and took longer to reach the first visible phloem contact $(P<0.0001)$ compared to single $\mathrm{Nr}: 1$ aphids (Table 2; Fig. 1c). The phloem phase consisted for $42 \%$ out of salivation for the aphids in the Nr:0 group versus $5 \%$ for single aphids $(P=0.0001)$. Additionally, the percentage of $\mathrm{Nr}: 1$ aphids displaying phloem ingestion was lower in an Nr:0 group compared to single aphids $(P=0.004)$. Performance was not affected (Table 3$)$.

\section{Effects of Macrosiphum euphorbiae}

No significant differences in EPG parameters were found between Nr:0 aphids feeding in a group of $M$. euphorbiae and single Nr:0 aphids on Terlana (Table 2; 5 in Appendix; Fig. 1b). Development time was higher in a group of $M$. euphorbiae compared to single Nr:0 aphids $(P=0.001)$ (Table 3). On Corbana, Nr:0 aphids in a group of $M$. euphorbiae showed a higher number of probes compared to single Nr:0 aphids $(P<0.0001)$. The age at death was higher in an $M$. euphorbiae group compared to single aphids on Corbana $(P=0.006)$.

$\mathrm{Nr}: 1$ aphids in a group of $M$. euphorbiae on Terlana spent less time on phloem phase $(P=0.001)$, a higher percentage of the phloem phase was spent on salivation $(P=0.003)$ and the number of probes was higher $(P=0.003)$ compared to single Nr:1 aphids (Table 2; Fig. 1d). Additionally, the percentage of aphids displaying phloem ingestion was lower in an $M$. euphorbiae group compared to single aphids $(P=0.010)$. Performance was not affected (Table 3). On Corbana, Nr:1 aphids in an $M$. euphorbiae group displayed also a higher number of probes $(P<0.0001)$ and less time was spent on phloem events $(P<0.0001)$, compared to single aphids. The percentage of time spent on salivation in the phloem phase was $5 \%$ for single Nr:1 aphids versus $47 \%$ for Nr:1 aphids in a $M$. euphorbiae group $(P<0.0001)$. The development time was longer in an M. euphorbiae group compared to single aphids Corbana $(P=0.007)$ (Table 3$)$.

\section{Effects of Myzus persicae}

The number of probes was higher when $\mathrm{Nr}: 0$ aphids were feeding in a group of $M$. persicae on both cultivar Terlana 

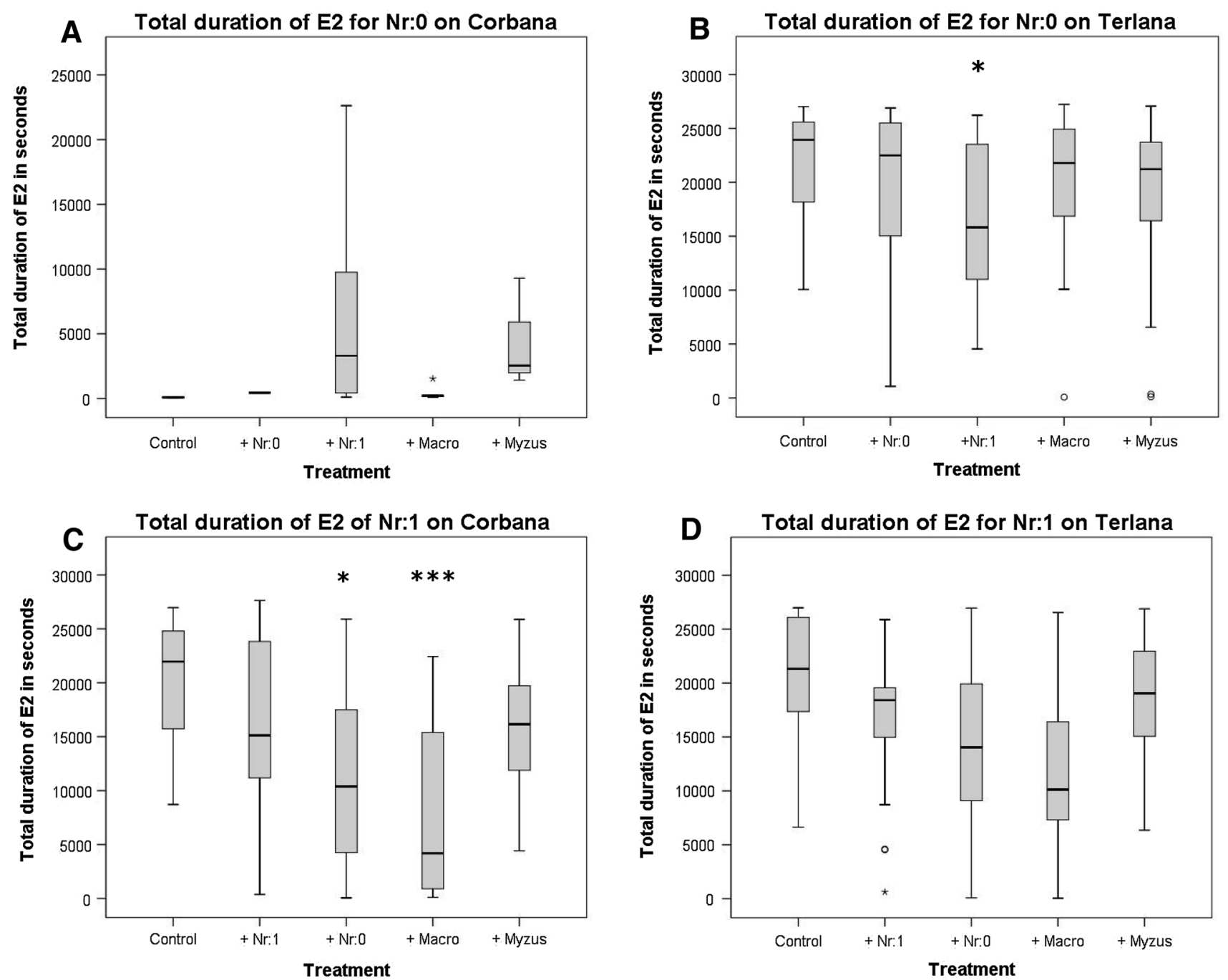

Fig. 1 The total duration of EPG parameter E2 (phloem ingestion) (median, first and third quartiles and range) for $N$. ribnisnigri $\mathrm{Nr}: 0$ on Corbana (A), Nr:0 on Terlana (B), Nr:1 on Corbana (C) and Nr:1 on Terlana (D) as single aphids (Control) or in a group of $\mathrm{Nr}: 0, \mathrm{Nr}: 1, M$. euphorbiae (Macro) and M. persicae (Myzus). Pairwise comparisons were made for total duration of E2 between plants without other

$(P=0.008)$ and Corbana $(P=0.001)$ compared to single Nr:0 aphids (Table 2). The age at death of Nr:0 aphids was higher in a group of $M$. persicae on Corbana compared to single Nr:0 aphids $(P=0.004)$ (Table 3$)$.

No significant differences were found between Nr:1 aphids on Terlana in an $M$. persicae group and single aphids. On Corbana, Nr:1 aphids within an $M$. persicae group displayed a higher number of probes $(P<0.0001)$, took longer to display the first phloem ingestion $(P=0.012)$ and spent less time on xylem feeding $(P=0.006)$ compared to single Nr:1 aphids (Table 2; 5 in Appendix). Development time was longer for aphids in an $M$. persicae group compared to single aphids on Corbana $(P=0.009)$.

aphids and plants with other aphids, and were analysed by the MannWhitney $U$ test, applying the Bonferroni correction to account for the four comparisons made by setting $\alpha=0.013$. Bars with bold asterisks differ significantly from the control plants. Outliers are plotted as asterisks and circles

\section{Discussion}

\section{Living in a group}

Some aphid species are known to benefit from living in groups. Aphis fabae and Brevicoryne brassicae are known to benefit from living in a colony (Dixon and Wratten 1971; Hayamizu 1984). B. brassicae showed enhanced growth and increased fecundity when living in a group, compared to solitary individuals, and enhanced nutritional quality of phloem sap is suggested as the underlying mechanism (Hayamizu 1984). Sandström et al. (2000) showed that aphid feeding resulted in enhanced nutritional quality of the phloem sap by higher concentrations of 
essential and other amino acids; however, this effect was shown to be species-specific; feeding by $S$. graminum and Diuraphis noxia Mordvilko increased the nutritional quality of the phloem sap, whereas feeding by $R$. padi did not. Enhanced susceptibility was also found for a susceptible tomato cultivar after pre-infestation of M. persicae (Civolani et al. 2010) and susceptible potato and peach varieties after conspecific pre-infestation of $M$. persicae or of $M$. euphorbiae (Dugravot et al. 2007; Sauge et al. 2002). However, on potato plants, these effects were only observed on previously infested leaves; systemic leaves showed a decrease in susceptibility, suggesting a systemicinduced resistance triggered by pre-infestation (Dugravot et al. 2007). This difference in effect between local and systemic leaves was also found by Prado and Tjallingii (2007) for B. brassicae on local and systemic pre-infested leaves of broccoli. Weng et al. (2005) showed that the duration of pre-infestation is important; infestation of wheat by $S$. graminum led to induced susceptibility after 2 days; however, after these two days, induced resistance was observed.

In our study, the aphids are not affected by feeding in a group of the same biotype. Both, Nr:0 on Corbana and Nr:1 on Terlana in a group of the same biotype, displayed a higher number of probes compared to single aphids, which are likely to be caused by disturbance of other aphids in the group; however, duration of phloem ingestion and performance was not affected.

\section{Defence suppression in lettuce}

It is unknown what mechanism underlies the virulence in $\mathrm{Nr}: 1$ aphids. Our data suggest that Nr:1 aphids are able to suppress the $\mathrm{Nr}$-based defence mechanism in resistant lettuce that is effective against $\mathrm{Nr}: 0$ aphids. In the absence of Nr:1 aphids, Nr:0 aphids did not survive the performance test on Corbana, whereas $15 \%$ survived and developed into adults in a group of Nr:1 aphids. Additionally, a significantly higher proportion of Nr:0 aphids in the Nr:1 group displayed phloem ingestion. This suppression, however, seems to be local and not spreading systemically, because only $15 \%$ of the $\mathrm{Nr}: 0$ aphids was benefitting. Nr:1 aphids might, for example, only be able to suppress the defence of one sieve tube, or one bundle of sieve tubes. Defence suppression for avirulent aphids was also found for $S$. graminum on resistant winter wheat by a virulent biotype (Dorschner et al. 1987). In contrast, a virulent biotype of the same aphid species on barley did not alter the feeding behaviour of an avirulent biotype (Hays et al. 1999). Similar results were found by Herbert et al. (Hebert et al. 2007) for the combination of a virulent and avirulent biotype of
M. euphorbiae on resistant and susceptible tomato. It should be noted that the above studies were performed employing pre-infestation, the aphids were removed before the actual experiment.

The interaction of piercing/sucking insects with their host plant has analogies with pathogen-plant interactions, both triggering mainly the SA-dependent pathway and in some cases the JA- and ethylene-dependent pathways (Walling 2000). Additionally, aphids were shown to induce the expression of genes involved in defences against pathogens (De Vos et al. 2005). For pathogens, the ability to overcome $R$-gene-based resistance is often attributed to the loss or modification of avirulence gene products, to evade the detection by the plant and/or suppressing plant defences through the injection of effectors, which is also hypothesised to be the underlying mechanism of aphid virulence (Hogenhout and Bos 2011; Parker and Gilbert 2004). Effectors are proteins that potentially interact with plant signalling cascades, and can suppress plant defence, modulate plant processes beneficial for aphid colonisation, and elicit effector-triggered resistance, by recognition of effectors by receptors involved in plant resistance (Carolan et al. 2011; Hogenhout and Bos 2011).

Several effectors have been identified in the past years in other aphid species (Bos et al. 2010; Carolan et al. 2009, 2011, 2014, 2015; De Vos and Jander 2009; Harmel et al. 2008; Nicholson et al. 2012; Vandermoten et al. 2014; Will et al. 2012). Some of these effectors are responsible for enhanced susceptibility, while others induced defences. A $M$. persicae effector was shown to enhance $M$. persicae fecundity, therefore being advantageous for the colonisation by this aphid species (Bos et al. 2010; Pitino and Hogenhout 2013). However, orthologs of this effector produced by Acyrthosiphon pisum (Harr.) had no effect on M. persicae (Pitino and Hogenhout 2013). Atamian et al. (2013) identified two M. euphorbiae effectors responsible for enhanced $M$. persicae fecundity in $N$. benthamiana. Only one of these was able to increase the fecundity of $M$. euphorbiae on tomato. Several other studies also identified effectors responsible for enhanced susceptibility (Elzinga et al. 2014; Mutti et al. 2008; Naessens et al. 2015; Pitino et al. 2011; Wang et al. 2015). Some effectors are able to induce defences. For example, De Vos and Jander (2009) identified proteinaceous elicitors from M. persicae, and Chaudhary et al. a saliva component (GROEL) from M. euphorbiae, that both are involved in inducing defences in Arabidopsis thaliana. Two candidate effectors were identified by Bos et al. (2010), and induced defences in Nicotiana benthamiana resulting in decreased aphid fecundity. It is of interest to identify the effector in the saliva of Nr:1 aphids that is responsible for the virulence and suppression of resistance against Nr:0. 


\section{Induced defence in lettuce}

In contrast to the defence suppression on Corbana, behaviour and performance of Nr:0 aphids are negatively affected by $\mathrm{Nr}: 1$ aphids on Terlana. Duration of phloem ingestion was shorter and, probably as a consequence, the development time longer in the presence of Nr:1. About $10 \%$ of the Nr:0 aphids did not even start phloem ingestion in the presence of Nr:1, during the $8 \mathrm{~h}$ of EPG recording. Additionally, the Nr:0 aphids in an Nr:1 group salivated more, indicating difficulties to overcome the wound response of lettuce by producing more watery saliva. Similar results were found for $\mathrm{Nr}: 1$ aphids feeding on Terlana together with $\mathrm{Nr}: 0$ aphids; more salivation, longer development time and $18 \%$ of the aphids did not start phloem ingestion. Both the virulent $\mathrm{Nr}: 1$ and avirulent Nr:0 aphids seem to increase defence in Terlana against the other biotype, which was not observed when they were feeding in a group of their own biotype. However, the overall survival did not differ. Resistance induced as a result of pre-infestation by the same biotype was also found in Medicago truncatula Gaertn. pre-infested by Acyrthosiphon kondoi Shinji (Klingler et al., 2005) and peach cv. Rubira pre-infested by M. persicae (Sauge et al. 2002), both decreasing the duration of phloem ingestion.

Nr:0 also increased resistance against Nr:1 on Corbana. Again, the phloem ingestion was shorter and the aphids salivated more. However, on the longer term, the survival and development time were not affected. We cannot prove that Nr:0 was actually feeding from Corbana, although stylet penetration should have taken place. The feeding behaviour of virulent $S$. graminum on resistant barley was also negatively affected by pre-infestation by an avirulent biotype; phloem ingestion was shorter and a larger number of probes was observed (Hays et al. 1999).

\section{The effect of heterospecific aphid species on $N$. ribisnigri}

A previous study showed that the $N r$-gene confers partial resistance against certain $M$. persicae isolates and has no effect on M. euphorbiae (Reinink and Dieleman 1989). The $M$. persicae biotype in our study was shown to be virulent on Corbana, performing and feeding equally well on both Corbana and Terlana. Only minor differences were found in EPG parameters and performance for M. euphorbiae on Terlana and Corbana plants (Table 4 in Appendix).

For $\mathrm{Nr}: 0$ and $\mathrm{Nr}: 1$ aphids in combination with $M$. euphorbiae and M. persicae, differences were found in the effect of the co-infesting aphid species, and also in the reaction of both biotypes to feeding by these species.

Macrosiphum euphorbiae seemed to increase defence in both Terlana and Corbana against Nr:1; the percentage of time spent on phloem salivation and number of probes was higher. Additionally, on Terlana, M. euphorbiae also caused a reduction in phloem ingestion. The increased defence in Terlana seems to be of short duration, because the development time and survival were not affected. On Corbana, the development time was negatively affected by $M$. euphorbiae, indicating a long-term increased defence by $M$. euphorbiae. Nr:1 was not affected by M. persicae on Terlana, whereas on Corbana defence was induced; the number of probes was higher; and the development time was longer.

For Nr:0 on Terlana, M. euphorbiae also increased the development time, but no differences were found in EPG parameters, indicating a slower induction of defence. On Corbana, only the number of probes was affected by $M$. euphorbiae. In contrast, Dugravot et al. (2007) found a reduction in the number of probes for M. persicae on potato after previous infestation by M. euphorbiae. Myzus persicae only increased the number of probes on both Corbana and Terlana for Nr:0.

As shown above, both biotypes react differently to the feeding or probing of M. euphorbiae and M. persicae, and $M$. euphorbiae and $M$. persicae might elicit different plant responses, therefore these interactions can be considered asymmetrical (Moran and Whitham 1990). On the one hand, plant responses to aphids are aphid species-specific (Messina et al. 2002), on the other hand, the response of an aphid species to aphid feeding-induced plant responses might also differ between aphid species (Smith and Boyko 2007). Therefore, the alteration in plant responses upon aphid feeding, may affect the fitness of other aphids negatively, positively or not at all (Petersen and Sandström 2001). This could be caused by the differences in composition of saliva between aphid species which might elicit different plant responses (Prado and Tjallingii 1997). Asymmetrical interactions between aphids were also found for D. noxia and R. padi on winter wheat (Messina et al. 2002), Monellia caryella Fitch and Melanocallis caryaefoliae Davis on pecan (Petersen and Sandström 2001) and for the root aphid Pemphigus betae (Doane) and the galling aphid Hayhurstia atriplicis (L.) on Chenopodium album plants (Moran and Whitham 1990).

Species of different taxonomic groups can also influence the feeding behaviour of aphids, for example, by induction of susceptibility by plant growth-promoting rhizobacterium (Pineda et al. 2012) and induced/increased resistance by endophytes (Siegel et al. 1990), nematodes (Ogallo and McClure 1996; Wurst and van der Putten 2007), caterpillars (Soler et al. 2012) and whiteflies (Xue et al. 2010).

\section{Conclusions}

Nasonovia ribisnigri biotypes are differently affected in their behaviour on resistant and susceptible lettuce by feeding or probing of conspecific and heterospecific aphids. Virulent 
biotype Nr:1 suppresses the absolute resistance in lettuce against Nr:0. On susceptible lettuce, co-infestation of one biotype led to induced defence against the other biotype. Induced defence was also observed on the resistant cultivar for $\mathrm{Nr}: 1$ upon co-infestation of $\mathrm{Nr}: 0, M$. persicae and $M$. euphorbiae. However, the induced defences only affected feeding behaviour and in some cases development time, but not survival. More information is needed about the effectors in the saliva of the aphids tested here, that are likely responsible for the suppression and induction of defence in lettuce, to better understand the mechanism of virulence in $N$. ribisnigri.

Acknowledgements Stichting TTI Groene Genetica (TTI-GG project 2CFD022RP) and Keygene N.V. are acknowledged for financial support. We acknowledge Martin de Vos for the useful scientific discussions.

Open Access This article is distributed under the terms of the Creative Commons Attribution 4.0 International License (http://crea tivecommons.org/licenses/by/4.0/), which permits unrestricted use, distribution, and reproduction in any medium, provided you give appropriate credit to the original author(s) and the source, provide a link to the Creative Commons license, and indicate if changes were made.

\section{Appendix}

See Tables 4 and 5 .

Table 4 EPG parameters (mean \pm SEM) of M. euphorbiae (Macro) and M. persicae (Myzus) on L. sativa cultivars, Corbana (C) and Terlana (T)

\begin{tabular}{|c|c|c|c|c|}
\hline & \multicolumn{2}{|c|}{ Macrosiphum euphorbiae } & \multicolumn{2}{|l|}{ Myzus persicae } \\
\hline & Corbana $(n=21)$ & Terlana $(n=19)$ & Corbana $(n=22)$ & Terlana $(n=19)$ \\
\hline Duration of first NP & $294 \pm 156$ & $200 \pm 125^{*}$ & $131 \pm 44$ & $150 \pm 39$ \\
\hline Duration of NP before 1st visible $\mathrm{E}$ & $1510 \pm 380$ & $1681 \pm 296$ & $1114 \pm 454$ & $645 \pm 124$ \\
\hline Number of probes to the 1st E1 & $4.90 \pm 0.53$ & $5.68 \pm 0.76$ & $7.09 \pm 1.24$ & $5.05 \pm 0.63$ \\
\hline Time to 1 st visible $\mathrm{E}$ from start 1 st probe & $3775 \pm 609$ & $4593 \pm 1244$ & $4636 \pm 861$ & $4288 \pm 569$ \\
\hline Total duration of $\mathrm{E}$ & $16,267 \pm 1500$ & $16,252 \pm 1919$ & $14,456 \pm 1647$ & $11,496 \pm 1877$ \\
\hline Total duration of E1 & $1580 \pm 304$ & $1404 \pm 322$ & $1654 \pm 415$ & $1870 \pm 364$ \\
\hline Contribution $\mathrm{E} 1$ to $\mathrm{E}(\%)$ & $13 \pm 3$ & $15 \pm 5$ & $25 \pm 7$ & $29 \pm 7$ \\
\hline Total duration of single E1 & $724 \pm 121$ & $938 \pm 192$ & $1378 \pm 433$ & $1331 \pm 337$ \\
\hline$\%$ aphids showing E2 & 100 & 100 & 91 & 95 \\
\hline Total duration of E2 & $14,687 \pm 1624$ & $14,847 \pm 2028$ & $14,083 \pm 1837$ & $10,161 \pm 2014$ \\
\hline Time to 1 st E2 from start 1st probe & $6126 \pm 1434$ & $8592 \pm 1900$ & $8936 \pm 1859$ & $9811 \pm 1660$ \\
\hline Time to 1st sustained E2 from start 1st probe & $9437 \pm 1697$ & $9538 \pm 1904$ & $7382 \pm 1429$ & $11118 \pm 1656$ \\
\hline Number of E2 periods & $2.90 \pm 0.34$ & $1.95 \pm 0.26$ & $1.82 \pm 0.27$ & $2.16 \pm 0.34$ \\
\hline Number of sustained E2 periods & $2.05 \pm 0.20$ & $1.58 \pm 0.21^{*}$ & $1.41 \pm 0.20$ & $1.37 \pm 0.23$ \\
\hline Total duration of NP & $3457 \pm 645$ & $3736 \pm 613$ & $2051 \pm 538$ & $2074 \pm 394$ \\
\hline Total duration of $\mathrm{C}$ & $7775 \pm 985$ & $7718 \pm 1255$ & $11117 \pm 1335$ & $14446 \pm 1651$ \\
\hline Total duration of $\mathrm{F}$ & & & $1653 \pm 283$ & $2973 \pm 1149$ \\
\hline Total duration of $\mathrm{G}$ & $2483 \pm 478$ & $2079 \pm 230$ & $2325 \pm 488$ & $1993 \pm 249$ \\
\hline Number of probes & $9.86 \pm 1.38$ & $10.32 \pm 1.60$ & $16.82 \pm 2.54$ & $14.68 \pm 1.97$ \\
\hline Number of short probes $(C<3 \mathrm{~min})$ & $4.76 \pm 1.15$ & $5.32 \pm 1.05$ & $8.05 \pm 1.87$ & $5.05 \pm 1.05$ \\
\hline
\end{tabular}

Pairwise comparisons were analysed by the Mann-Whitney $U$ test. Significance of differences in percentage of aphids showing E2 was analysed by Fisher's exact test. Time parameters are in seconds

$N P$ non-penetration, $C$ pathway, $E$ phloem event, $E 1$ phloem salivation, $E 2$ phloem ingestion, $G$ xylem ingestion, $F$ penetration difficulties $* P<0.05 ; * * P<0.005 ; * * * P<0.001$

Table 5 EPG parameters (mean \pm SEM) of $N$. ribisnigri population Nr:0 and Nr:1 on L. sativa cultivars, Corbana (C) and Terlana (T) as single aphids or in a group of Nr:0, Nr:1, M. euphorbiae (Macro) and M. persicae (Myzus)

\begin{tabular}{llllrr}
\hline Test aphid: Nr:0 & T & T + Nr:0 & T + Nr:1 & T + Macro & T + Myzus \\
\hline Duration of NP before 1st visible E & $1619 \pm 255$ & $2281 \pm 609$ & $1884 \pm 358$ & $2222 \pm 491$ & $2107 \pm 402$ \\
Time to 1st E2 from start 1st probe & $6414 \pm 1070$ & $7022 \pm 1242$ & $8718 \pm 1484$ & $6519 \pm 1026$ & $6438 \pm 837$ \\
Time to 1st sustained E2 from start 1st probe & $6414 \pm 1070$ & $7419 \pm 1366$ & $8984 \pm 1498$ & $7229 \pm 1079$ & $6063 \pm 711$ \\
\hline
\end{tabular}


Table 5 continued

\begin{tabular}{|c|c|c|c|c|c|}
\hline Test aphid: Nr:0 & $\mathrm{T}$ & $\mathrm{T}+\mathrm{Nr}: 0$ & $\mathrm{~T}+\mathrm{Nr}: 1$ & $\mathrm{~T}+$ Macro & $\mathrm{T}+$ Myzus \\
\hline Total duration of $\mathrm{E}$ & $21,933 \pm 1083$ & $19,954 \pm 1738$ & $15,513 \pm 1662^{* *}$ & $20,280 \pm 1429$ & $17,254 \pm 2050$ \\
\hline Total duration of E1 & $294 \pm 78$ & $723 \pm 249$ & $664 \pm 98 * *$ & $382 \pm 140$ & $857 \pm 245$ \\
\hline Total duration of single E1 & $197 \pm 58$ & $267 \pm 62$ & $427 \pm 120$ & $184 \pm 31$ & $339 \pm 90$ \\
\hline Number of E2 periods & $1.20 \pm 0.12$ & $1.52 \pm 0.37$ & $1.30 \pm 0.20$ & $1.38 \pm 0.13$ & $1.45 \pm 0.26$ \\
\hline Number of sustained E2 periods & $1.15 \pm 0.08$ & $1.00 \pm 0.14$ & $1.04 \pm 0.12$ & $1.05 \pm 0.08$ & $1.14 \pm 0.21$ \\
\hline Number of probes to the 1st E1 & $8.15 \pm 1.51$ & $8.11 \pm 1.76$ & $7.23 \pm 1.00$ & $7.67 \pm 1.17$ & $8.67 \pm 0.96$ \\
\hline Total duration of NP & $1753 \pm 329$ & $2786 \pm 654$ & $2611 \pm 465$ & $2834 \pm 659$ & $3692 \pm 765$ \\
\hline Total duration of $\mathrm{C}$ & $4923 \pm 848$ & $7466 \pm 1344$ & $8818 \pm 1150^{*}$ & $5151 \pm 873$ & $7758 \pm 1275$ \\
\hline Total duration of $\mathrm{F}$ & & $3049 \pm 462$ & & 3858 & $1984 \pm 1656$ \\
\hline Total duration of $\mathrm{G}$ & $1912 \pm 211$ & $4532 \pm 2020$ & $3882 \pm 856$ & $2462 \pm 497$ & $2569 \pm 298$ \\
\hline Number of short probes $(C<3 \mathrm{~min})$ & $4.85 \pm 1.19$ & $6.10 \pm 1.46$ & $6.30 \pm 1.08$ & $6.76 \pm 1.48$ & $8.91 \pm 1.96$ \\
\hline Test aphid: Nr:0 & $\mathrm{C}$ & $\mathrm{C}+\mathrm{Nr}: 0$ & $\mathrm{C}+\mathrm{Nr}: 1$ & $\mathrm{C}+$ Macro & $\mathrm{C}+$ Myzus \\
\hline Duration of NP before 1st visible E & $2786 \pm 688$ & $5671 \pm 1049$ & $2728 \pm 685$ & $3614 \pm 721$ & $5699 \pm 864 * *$ \\
\hline Time to 1 st E2 from start 1st probe & $13640 \pm 5614$ & 11701 & $12103 \pm 2611$ & $12087 \pm 2365$ & $8164 \pm 4349$ \\
\hline Time to 1st sustained E2 from start 1st probe & & & $12451 \pm 3648$ & 7055 & $14532 \pm 4696$ \\
\hline Total duration of $\mathrm{E}$ & $434 \pm 97$ & $393 \pm 97$ & $3580 \pm 1467$ & $372 \pm 115$ & $1594 \pm 718$ \\
\hline Total duration of E1 & $424 \pm 96$ & $361 \pm 78$ & $821 \pm 209$ & $254 \pm 47$ & $814 \pm 270$ \\
\hline Total duration of single E1 & $403 \pm 94$ & $348 \pm 73$ & $405 \pm 106$ & $182 \pm 33$ & $490 \pm 130$ \\
\hline Number of E2 periods & $0.11 \pm 0.07$ & $0.06 \pm 0.06$ & $0.68 \pm 0.24$ & $0.29 \pm 0.12$ & $0.43 \pm 0.28$ \\
\hline Number of sustained E2 periods & $0.00 \pm 0.00$ & $0.00 \pm 0.00$ & $0.32 \pm 0.13$ & $0.05 \pm 0.05$ & $0.22 \pm 0.13$ \\
\hline Number of probes to the 1st E1 & $7.83 \pm 1.16$ & $17.86 \pm 2.16^{* * *}$ & $12.67 \pm 1.84$ & $18.74 \pm 2.55^{* *}$ & $15.59 \pm 2.10^{*}$ \\
\hline Total duration of NP & $7095 \pm 944$ & $9572 \pm 820$ & $6282 \pm 822$ & $8635 \pm 893$ & $9531 \pm 765$ \\
\hline Total duration of $\mathrm{C}$ & $19,283 \pm 769$ & $16,957 \pm 707$ & $16,932 \pm 1179$ & $17,543 \pm 664$ & $16,091 \pm 748^{*}$ \\
\hline Total duration of $\mathrm{F}$ & & 3896 & & $890 \pm 240$ & 4990 \\
\hline Total duration of $\mathrm{G}$ & $2881 \pm 556$ & $3150 \pm 813$ & $3476 \pm 759$ & $3082 \pm 765$ & $2408 \pm 372$ \\
\hline Number of short probes $(C<3 \mathrm{~min})$ & $11.58 \pm 1.84$ & $25.89 \pm 3.51^{* *}$ & $17.84 \pm 2.78$ & $26.90 \pm 2.74 * * *$ & $24.78 \pm 2.97 * *$ \\
\hline Test aphid: Nr:1 & $\mathrm{T}$ & $\mathrm{T}+\mathrm{Nr}: 1$ & $\mathrm{~T}+\mathrm{Nr}: 0$ & $\mathrm{~T}+$ Macro & $\mathrm{T}+$ Myzus \\
\hline Duration of NP before 1st visible $\mathrm{E}$ & $1391 \pm 271$ & $1825 \pm 332$ & $1701 \pm 383$ & $3413 \pm 915$ & $1986 \pm 576$ \\
\hline Time to 1 st E2 from start 1st probe & $5373 \pm 1002$ & $7684 \pm 1030$ & $8533 \pm 1420$ & $6337 \pm 1022$ & $6167 \pm 1390$ \\
\hline Time to 1st sustained E2 from start 1st probe & $5925 \pm 1094$ & $9395 \pm 1317$ & $9180 \pm 1495$ & $7713 \pm 1187$ & $6433 \pm 1350$ \\
\hline Total duration of $\mathrm{E}$ & $21,405 \pm 1205$ & $17,307 \pm 1367$ & $13,370 \pm 1959 * *$ & $11,799 \pm 1975^{* *}$ & $17,523 \pm 1907$ \\
\hline Total duration of E1 & $767 \pm 262$ & $739 \pm 119$ & $662 \pm 125$ & $1015 \pm 348$ & $1025 \pm 380$ \\
\hline Total duration of single E1 & $250 \pm 40$ & $356 \pm 69$ & $372 \pm 69$ & $714 \pm 348$ & $624 \pm 196$ \\
\hline Number of E2 periods & $6.95 \pm 1.45$ & $6.36 \pm 0.93$ & $6.40 \pm 0.83$ & $8.16 \pm 1.37$ & $9.53 \pm 2.41$ \\
\hline Number of sustained E2 periods & $1.47 \pm 0.14$ & $1.86 \pm 0.20$ & $1.09 \pm 0.16$ & $1.65 \pm 0.27$ & $1.65 \pm 0.28$ \\
\hline Number of probes to the 1 st E1 & $1.37 \pm 0.11$ & $1.27 \pm 0.12$ & $0.86 \pm 0.14^{*}$ & $1.25 \pm 0.22$ & $1.41 \pm 0.21$ \\
\hline Total duration of NP & $1952 \pm 393$ & $3507 \pm 395$ & $3264 \pm 524$ & $6574 \pm 1106^{* * *}$ & $3162 \pm 649$ \\
\hline Total duration of $\mathrm{C}$ & $4563 \pm 801$ & $6978 \pm 811$ & $11,156 \pm 1428 * * *$ & $10,295 \pm 1104 * * *$ & $7484 \pm 1368$ \\
\hline Total duration of $\mathrm{F}$ & $2610 \pm 1471$ & & & $2178 \pm 772$ & \\
\hline Total duration of $\mathrm{G}$ & $2877 \pm 820$ & $3045 \pm 611$ & $4894 \pm 1304$ & $2519 \pm 375$ & $1786 \pm 396$ \\
\hline Number of short probes $(C<3 \mathrm{~min})$ & $5.16 \pm 1.20$ & $9.00 \pm 1.20$ & $6.00 \pm 0.87$ & $12.80 \pm 2.44^{*}$ & $9.47 \pm 2.49$ \\
\hline Test aphid: Nr:1 & $\mathrm{C}$ & $\mathrm{C}+\mathrm{Nr}: 1$ & $\mathrm{C}+\mathrm{Nr}: 0$ & $\mathrm{C}+$ Macro & $\mathrm{C}+$ Myzus \\
\hline Duration of NP before 1 st visible $\mathrm{E}$ & $993 \pm 168$ & $2454 \pm 636$ & $3678 \pm 666^{* * *}$ & $2630 \pm 489 * *$ & $2980 \pm 576^{* *}$ \\
\hline Time to 1 st E2 from start 1st probe & $5563 \pm 1015$ & $6194 \pm 1360$ & $12,842 \pm 1783 * *$ & $9829 \pm 1886$ & $8652 \pm 1229^{*}$ \\
\hline Time to 1 st sustained E2 from start 1st probe & $6673 \pm 1122$ & $9687 \pm 1903$ & $12,744 \pm 2138$ & $13,111 \pm 2737$ & $8652 \pm 1229$ \\
\hline
\end{tabular}


Table 5 continued

\begin{tabular}{|c|c|c|c|c|c|}
\hline Test aphid: Nr:1 & $\mathrm{C}$ & $\mathrm{C}+\mathrm{Nr}: 1$ & $\mathrm{C}+\mathrm{Nr}: 0$ & $\mathrm{C}+$ Macro & $\mathrm{C}+$ Myzus \\
\hline Total duration of $\mathrm{E}$ & $20,634 \pm 1249$ & $15,530 \pm 2158$ & $9760 \pm 2145^{* * *}$ & $6303 \pm 1872 * * *$ & $17,039 \pm 1185$ \\
\hline Total duration of E1 & $773 \pm 186$ & $617 \pm 147$ & $1055 \pm 189$ & $637 \pm 118$ & $701 \pm 155$ \\
\hline Total duration of single E1 & $667 \pm 235$ & $461 \pm 136$ & $576 \pm 142$ & $447 \pm 120$ & $401 \pm 106$ \\
\hline Number of E2 periods & $4.20 \pm 0.34$ & $7.06 \pm 1.23$ & $13.71 \pm 2.79 *$ & $10.28 \pm 1.47 * * *$ & $11.61 \pm 1.91 * *$ \\
\hline Number of sustained E2 periods & $1.75 \pm 0.20$ & $1.72 \pm 0.24$ & $0.90 \pm 0.18^{* *}$ & $1.50 \pm 0.35$ & $1.37 \pm 0.14$ \\
\hline Number of probes to the 1 st E1 & $1.50 \pm 0.15$ & $1.17 \pm 0.17$ & $0.65 \pm 0.15 * * *$ & $0.56 \pm 0.15 * * *$ & $1.37 \pm 0.14$ \\
\hline Total duration of NP & $1788 \pm 360$ & $4790 \pm 1082$ & $5260 \pm 721 * * *$ & $7135 \pm 974 * * *$ & $3815 \pm 559 * *$ \\
\hline Total duration of $\mathrm{C}$ & $4984 \pm 743$ & $7588 \pm 1191$ & $12589 \pm 1335^{* * *}$ & $13566 \pm 1262 * * *$ & $7596 \pm 1041$ \\
\hline Total duration of $\mathrm{F}$ & 2697 & 1925 & 3620 & $3403 \pm 1181$ & \\
\hline Total duration of $\mathrm{G}$ & $4198 \pm 1178$ & $2341 \pm 703$ & $4497 \pm 912$ & $3100 \pm 1502$ & $1579 \pm 123 *$ \\
\hline Number of short probes $(C<3 \mathrm{~min})$ & $3.85 \pm 1.11$ & $9.61 \pm 2.47$ & $11.10 \pm 2.28^{*}$ & $16.94 \pm 3.07 * * *$ & $10.74 \pm 1.63 * * *$ \\
\hline
\end{tabular}

Pairwise comparisons were made for EPG parameters between plants without other aphids and plants with other aphids, and were analysed by the Mann-Whitney $U$ test, applying the Bonferroni correction to account for the four comparisons made by setting $\alpha=0.013$. Significance of differences in percentage of aphids showing E2 was analysed by Fisher's exact test. Time parameters are in seconds

$N P$ non-penetration, $C$ pathway, $E$ phloem event, $E 1$ phloem salivation, $E 2$ phloem ingestion, $G$ xylem ingestion, $F$ penetration difficulties

$* P<0.013 ; * * P<0.005 ; * * * P<0.001$

\section{References}

Atamian HS, Chaudhary R, Cin VD, Bao E, Girke T, Kaloshian I (2013) In planta expression or delivery of potato aphid Macrosiphum euphorbiae effectors Me10 and Me23 enhances aphid fecundity. Mol Plant Microbe Interact 26:67-74. doi:10. 1094/mpmi-06-12-0144-fi

Bos JIB, Prince D, Pitino M, Maffei ME, Win J, Hogenhout SA (2010) A functional genomics approach identifies candidate effectors from the aphid species Myzus persicae (green peach aphid). PLoS Genet 6:e1001216. doi:10.1371/journal.pgen. 1001216

Carolan JC, Fitzroy CIJ, Ashton PD, Douglas AE, Wilkinson TL (2009) The secreted salivary proteome of the pea aphid Acyrthosiphon pisum characterised by mass spectrometry. Proteomics 9:2457-2467

Carolan JC et al. (2011) Predicted effector molecules in the salivary secretome of the pea aphid (Acyrthosiphon pisum): a dual transcriptomic/proteomic approach. J Proteome Res 10:1505-1518

Chaudhary R, Atamian HS, Shen Z, Briggs SP, Kaloshian I (2014) GroEL from the endosymbiont Buchnera aphidicola betrays the aphid by triggering plant defense. Proc Natl Acad Sci 111:8919-8924

Chaudhary R, Atamian HS, Shen Z, Briggs SP, Kaloshian I (2015) Potato aphid salivary proteome: enhanced salivation using resorcinol and identification of aphid phosphoproteins. J Proteome Res 14:1762-1778

Cherqui A, Tjallingii WF (2000) Salivary proteins of aphids, a pilot study on identification, separation and immunolocalisation. J Insect Physiol 46:1177-1186

Civolani S et al (2010) Probing behaviour of Myzus persicae on tomato plants containing Mi gene or BTH-treated evaluated by electrical penetration graph. Bull Insect 63:265-271

De Vos M, Jander G (2009) Myzus persicae (green peach aphid) salivary components induce defence responses in Arabidopsis thaliana. Plant Cell Environ 32:1548-1560

De Vos M et al (2005) Signal signature and transcriptome changes of Arabidopsis during pathogen and insect attack. Mol Plant Microbe Interact 18:923-937. doi:10.1094/mpmi-18-0923
Dixon A, Wratten S (1971) Laboratory studies on aggregation, size and fecundity in the black bean aphid, Aphis fabae Scop. Bull Entomol Res 61:97-111

Dorschner KW, Ryan JD, Johnson RC, Eikenbary RD (1987) Modification of host nitrogen levels by the greenbug (Homoptera, Aphididae) SW- Its role in resistance of winter-wheat to aphids. Environ Entomol 16:1007-1011

Dugravot S, Brunissen L, Létocart E, Tjallingii WF, Vincent C, Giordanengo P, Cherqui A (2007) Local and systemic responses induced by aphids in Solanum tuberosum plants. Entomol Exp Appl 123:271-277. doi:10.1111/j.1570-7458.2007.00542.x

Elzinga DA, De Vos M, Jander G (2014) Suppression of plant defenses by a Myzus persicae (green peach aphid) salivary effector protein. Mol Plant Microbe Interact 27:747-756. doi:10. 1094/mpmi-01-14-0018-r

Harmel $\mathrm{N}$ et al (2008) Identification of aphid salivary proteins: a proteomic investigation of Myzus persicae. Insect Mol Biol $17: 165-174$

Hayamizu E (1984) Comparative studies on aggregations among aphids in relation to population dynamics: II Effects of aggregation on the growth and fecundity of Brevicoryne brassicae L. and Myzus persicae: SULZER: Homoptera: Aphididae. Appl Entomol Zool 19:468-475

Hays DB, Porter DR, Webster JA, Carver BF (1999) Feeding behavior of biotypes $\mathrm{E}$ and $\mathrm{H}$ greenbug (Homoptera: Aphididae) on previously infested near-isolines of barley. J Econ Entomol 92:1223-1229

Hebert SL, Jia L, Goggin FL (2007) Quantitative differences in aphid virulence and foliar symptom development on tomato plants carrying the Mi resistance gene. Environ Entomol 36:458-467

Hogenhout SA, Bos JIB (2011) Effector proteins that modulate plantinsect interactions. Curr Opin Plant Biol 14:422-428. doi:10. 1016/j.pbi.2011.05.003

McCreight JD (2008) Potential sources of genetic resistance in Lactuca spp. to the lettuce aphid, Nasonovia ribisnigri (Mosely) (Homoptera: Aphididae). HortScience 43:1355-1358

Messina FJ, Taylor R, Karren ME (2002) Divergent responses of two cereal aphids to previous infestation of their host plant. Entomol Exp Appl 103:43-50. doi:10.1046/j.1570-7458.2002.00956.x 
Moran NA, Whitham TG (1990) Interspecific competition between root-feeding and leaf-galling aphids mediated by host-plant resistance. Ecology 71:1050-1058. doi:10.2307/1937373

Mutti NS et al (2008) A protein from the salivary glands of the pea aphid, Acyrthosiphon pisum, is essential in feeding on a host plant. Proc Natl Acad Sci 105:9965-9969

Naessens E, Dubreuil G, Giordanengo P, Baron OL, Minet-Kebdani N, Keller H, Coustau C (2015) A secreted MIF cytokine enables aphid feeding and represses plant immune responses. Curr Biol 25:1898-1903

Nicholson SJ, Hartson SD, Puterka GJ (2012) Proteomic analysis of secreted saliva from Russian Wheat Aphid (Diuraphis noxia Kurd.) biotypes that differ in virulence to wheat. J Proteomics 75:2252-2268

Ogallo JL, McClure MA (1996) Systemic acquired resistance and susceptibility to root-knot nematodes in tomato. Phytopathology $86: 498-501$

Parker IM, Gilbert GS (2004) The evolutionary ecology of novel plant-pathogen interactions. Ann Rev Ecol Evol Syst 35:675-700

Petersen MK, Sandström JP (2001) Outcome of indirect competition between two aphid species mediated by responses in their common host plant. Funct Ecol 15:525-534. doi:10.1046/j.02698463.2001.00552.x

Pineda A, Zheng SJ, van Loon JJA, Dicke M (2012) Rhizobacteria modify plant-aphid interactions: a case of induced systemic susceptibility. Plant Biol 14:83-90

Pitino M, Hogenhout SA (2013) Aphid protein effectors promote aphid colonization in a plant species-specific manner. Mol Plant Microbe Interact 26:130-139

Pitino M, Coleman AD, Maffei ME, Ridout CJ, Hogenhout SA (2011) Silencing of aphid genes by dsRNA feeding from plants. PLoS ONE 6:e25709

Prado E, Tjallingii WF (1997) Effects of previous plant infestation on sieve element acceptance by two aphids. Entomol Exp Appl 82:189-200

Prado E, Tjallingii WF (2007) Behavioral evidence for local reduction of aphid-induced resistance. J Insect Sci 7:1-8

Reinink K, Dieleman FL (1989) Comparison of sources of resistance to leaf aphids in lettuce (Lactuca sativa L.). Euphytica 40:21-29

Sandström J, Telang A, Moran N (2000) Nutritional enhancement of host plants by aphids-a comparison of three aphid species on grasses. J Insect Physiol 46:33-40

Sarria E, Cid M, Garzo E, Fereres A (2009) Excel Workbook for automatic parameter calculation of EPG data. Comput Electron Agric 67:35-42

Sauge MH, Lacroze JP, Poëssel JL, Pascal T, Kervella J (2002) Induced resistance by Myzus persicae in the peach cultivar 'Rubira'. Entomol Exp Appl 102:29-37
Siegel MR et al (1990) Fungal endophyte-infected grasses: alkaloid accumulation and aphid response. J Chem Ecol 16:3301-3315. doi:10.1007/bf00982100

Smith CM, Boyko EV (2007) The molecular bases of plant resistance and defense responses to aphid feeding: current status. Entomol Exp Appl 122:1-16

Soler R, Badenes-Pérez FR, Broekgaarden C, Zheng S-J, David A, Boland W, Dicke M (2012) Plant-mediated facilitation between a leaf-feeding and a phloem-feeding insect in a brassicaceous plant: from insect performance to gene transcription. Funct Ecol 26:156-166. doi:10.1111/j.1365-2435.2011.01902.x

Ten Broeke CJM, Dicke M, Van Loon JJA (2013) Performance and feeding behaviour of two biotypes of the black currant-lettuce aphid, Nasonovia ribisnigri, on resistant and susceptible Lactuca sativa near-isogenic lines. Bull Entomol Res. 103:511-521

ten Broeke CJM, Dicke M, van Loon JJA (2016) Feeding behavior and performance of Nasonovia ribisnigri on grafts, detached leaves, and leaf disks of resistant and susceptible lettuce. Entomol Exp Appl 159:102-111. doi:10.1111/eea.12430

Thabuis APP, Teekens KC, Van Herwijnen ZO (2011) Lettuce that is resistant to the lettuce aphid Nasonovia ribisnigri biotype 1 World Intellectual Property Organization PCT/EP2010/067588

Vandermoten S, Harmel N, Mazzucchelli G, De Pauw E, Haubruge E, Francis $F$ (2014) Comparative analyses of salivary proteins from three aphid species. Insect Mol Biol 23:67-77. doi:10.1111/imb. 12061

Walling LL (2000) The myriad plant responses to herbivores. J Plant Growth Regul 19:195-216

Wang W et al (2015) Armet is an effector protein mediating aphidplant interactions. FASEB J 29:2032-2045. doi:10.1096/fj.14266023

Weng Y, Michels GJ Jr, Lazar MD, Rudd JC (2005) Spatial and temporal distribution of induced resistance to greenbug (Homoptera: Aphididae) herbivory in preconditioned resistant and susceptible near isogenic plants of wheat. J Econ Entomol 98:1024-1031

Will T, Tjallingii WF, Thönnessen A, Van Bel AJE (2007) Molecular sabotage of plant defense by aphid saliva. Proc Natl Acad Sci USA 104:10536-10541

Will T, Steckbauer K, Hardt M, van Bel AJ (2012) Aphid gel saliva: sheath structure, protein composition and secretory dependence on stylet-tip milieu. PLoS ONE 7:e46903

Wurst S, van der Putten WH (2007) Root herbivore identity matters in plant-mediated interactions between root and shoot herbivores. Basic Appl Ecol 8:491-499. doi:10.1016/j.baae.2006.09.015

Xue M, Wang CX, Bi MJ, Li QL, Liu TX (2010) Induced defense by Bemisia tabaci Biotype B (Hemiptera: Aleyrodidae) in tobacco against Myzus persicae (Hemiptera: Aphididae). Environ Entomol 39:883-891. doi:10.1603/en09307 